\title{
La complejidad y el diálogo transdisciplinario de saberes"
}

\author{
Capítulo del libro La revolución contemporánea del saber y la \\ complejidad social. Hacia unas ciencias sociales de nuevo tipo
}

\author{
Pedro Luis Sotolongo Codina** \\ (pedro.sotolongo@infomed.sld.cu)
}

Carlos Jesús Delgado Díaz ${ }^{* * *}$

(carlosd@ffh.uh.cu)

Examinaremos en este capítulo otra faceta del enfoque 'de la Complejidad' que también lo emparenta con las otras manifestaciones de ruptura con el ideal clásico -disciplinario- de racionalidad: su índole transdisciplinaria, condicionadora de la necesidad de un diálogo entre saberes.

Ello completará -junto a lo tratado en los tres capítulos anteriores ${ }^{-1}$ un primer nivel de generalidad en nuestro libro: el de una panorámica teórica 'de la Complejidad' como parte integrante de la revolución contemporánea del saber.

* $\quad$ Fuente original en SOTOLONGO CODINA, P. L. y DELGADO DÍAZ, C. J. (2006). Capítulo IV. La complejidad y el diálogo transdiscipliario de saberes. En La revolución contemporánea del saber y la complejidad social. Hacia unas ciencias sociales de nuevo tipo, pp. 65-77. Buenos Aires, Argentina: Consejo Latinoamericano de Ciencias Sociales (CLACSO). Recuperado desde https://goo.gl/ZYtNG5 - La versión completa del libro está disponible para su descarga libre e irrestricta desde https://goo.gl/pzvhdt - Agradecimientos especiales a los profesores Pedro Luis Sotolongo Codina y Carlos Jesús Delgado Díaz, así como a Lucas Sablich, coordinador editorial CLACSO, por permitirnos publicar estas cuantas líneas sobre la transdisciplinariedad. Todas notas pie de páginas fueron agregadas por el Equipo Editorial de la revista Trans-pasando Fronteras.

** Master of Sciences en Física y Doctor en Filosofía. Investigador titular del Instituto de Filosofía y la Escuela Nacional de Salud Publica, La Habana, Cuba.

** Filósofo y Master of Arts en Filosofía de Universidad Estatal de Bielorrusia (1983); Doctor en Ciencias Filosóficas (Cuba 1992) y profesor titular de la Universidad de La Habana, Cuba.

1 Los primero tres capítulos del libro son: I. El nuevo saber en construcción y las ciencias sociales, II. La complejidad y el nuevo ideal de racionalidad, y III. La epistemología hermenéutica de segundo orden (ver: https://goo.gl/pzvhdt). 
Sin embargo, antes de abordar "lo transdisciplinario" vinculado al enfoque "de la Complejidad', estimamos conveniente dilucidar su correlación con "lo multidisciplinario" y "lo interdisciplinario", aunque sea porque en ocasiones, en debates, ensayos y artículos, se constata cierta promiscuidad en la utilización de dichos términos.

\section{Multidisciplina, interdisciplina y transdisciplina: ¿Antagonismo o complementariedad?}

A juicio nuestro conviene distinguir, en lo posible, el ámbito de "lo multidisciplinario", el de "lo interdisciplinario" y el de "lo transdisciplinario", si bien no debemos aspirar a trazar entre ellos fronteras demasiado rígidas e inflexibles, sino que, por el contrario, debemos estar prestos a admitirlas cuando así se nos manifiesten como difusas y flexibles. Difusas y flexibles, sí, pero existentes y delimitables en calidad de tales.

Ante todo, habría que decir que la interdisciplina presupone ya, en un cierto sentido que explicitaremos, la multidisciplina. Expliquémonos: entendemos a la multidisciplina como el esfuerzo indagatorio convergente de varias disciplinas diferentes hacia el abordaje de un mismo problema o situación a dilucidar. Por lo general, tal problema o situación ha venido siendo indagado por una u otra disciplina como su objeto de estudio y, en cierto momento, dicho objeto de estudio comienza a ser abordado "multidisciplinariamente" con el concurso convergente (a veces de los métodos, a veces de los desarrollos conceptuales) de otras disciplinas. La Bioquímica y la Biofísica, entre otras, se ofrecen como ejemplos de la multidisciplina.

Por otra parte, la interdisciplina la comprendemos como aquel esfuerzo indagatorio, también convergente, entre varias disciplinas -y, por lo mismo, en ese sentido, presupone la multidisciplinariedad- pero que persigue el objetivo de obtener "cuotas de saber" acerca de un objeto de estudio nuevo, diferente a los objetos de estudio que pudieran estar previamente delimitados disciplinaria o incluso multidisciplinariamente. La Ingeniería Genética y la Inteligencia Artificial, entre otras, se ofrecen como ejemplos de la interdisciplina.

Por lo mismo, la interdisciplina es una empresa indagatoria más ambiciosa que la multidisciplina. Si esta última encuentra uno u otro objeto de indagación más o menos delimitado disciplinariamente, aquella, como parte de sus esfuerzos indagatorios, tiene que delimitar interdisciplinariamente un objeto de estudio previamente no delimitado discipli- 
nariamente. Y obtener "cuotas de nuevo saber" acerca del mismo. Por ello es que, a nuestro juicio, se habla mucho más de interdisciplina que la que realmente se lleva cabo, siendo en realidad multidisciplinarias muchas de las pretendidas iniciativas interdisciplinarias.

A su vez, reconocemos a la transdisciplina como el esfuerzo indagatorio que persigue obtener "cuotas de saber" análogas sobre diferentes objetos de estudio disciplinarios, multidisciplinarios o interdisciplinarios -incluso aparentemente muy alejados y divergentes entre sí- articulándolas de manera que vayan conformando un corpus de conocimientos que trasciende cualquiera de dichas disciplinas, multidisciplinas e interdisciplinas. El enfoque 'de la Complejidad', la Bioética Global, el Holismo Ambientalista, entre otros, se ofrecen como ejemplos de la transdisciplina.

De lo expresado se desprende que la multidisciplina, la interdisciplina y la transdisciplina son en realidad esfuerzos indagatorios que, lejos de contradecirse, se complementan. En el caso de la multidisciplina y la interdisciplina, tal complementariedad es obvia; de hecho, la última presupone la primera en un cierto sentido ya aludido. Menos evidente es la complementariedad entre multidisciplina y transdisciplina o entre interdisciplina y transdisciplina, si bien esta se halla en la circunstancia-que examinaremos más de cerca para el caso del enfoque transdisciplinario 'de la Complejidad'- de que uno u otro corpus de saber transdisciplinarios, si bien trascienden lo disciplinario, lo multidisciplinario y lo interdisciplinario, se nutren de dichos ámbitos indagatorios y los pertrechan y fecundan con sus propios resultados conceptuales, metodológicos y/o metódicos transdisciplinarios.

\section{La índole transdisciplinaria del enfoque 'de la complejidad'. ¿Elimina la transdisciplinariedad a las disciplinas?}

En ocasiones se afirma que el advenimiento de la multidisciplina, la interdisciplina y, sobre todo, la transdisciplina "eliminará" a las disciplinas. El caso de la índole transdisciplinaria del enfoque 'de la Complejidad', que es el más central para nuestros propósitos, nos brinda la ocasión para dilucidar la supuesta "eliminación" de las disciplinas por la transdisciplina.

La historia del surgimiento del enfoque 'de la Complejidad' constituye un fehaciente desmentido a la aludida afirmación acerca de la "eliminación" de las disciplinas. Tal historia -desde las primeras décadas del siglo XX, con mayor intensidad y evidencia en 
su segundo tercio, hasta la eclosión como tal del campo que hoy denominamos teoría o enfoque 'de la Complejidad' en la década del ochenta de dicho siglo- atestigua cómo su corpus transdisciplinario (conceptual, metodológico y metódico) de conocimientos se ha ido constituyendo a partir de una u otra disciplina (por cierto de numerosas de ellas, exactas, naturales, técnicas y sociales) y, con posterioridad, las ha nutrido con lo elaborado transdisciplinariamente.

Así, nociones hoy arquetípicas del enfoque 'de la Complejidad', como "caos", "atractores", "espacio de fases", fueron asimiladas desde los estudios de la Dinámica Física; otras, como las nociones de "estructuras disipativas" y "ciclos autocatalíticos", se incorporaron desde la Termodinámica Física o Química y/o la Químico-Física; nociones como las de "bifurcaciones" y "fractales" usufructuaron desarrollos de la Dinámica Física y las Matemáticas; y la de "borrosidad” se incorporó desde la Lógica y las Ciencias Sociales; por su parte, las de "red dis tribuida", "red de redes", "retroalimentaciones", "conectividad", fueron tomadas de la Cibernética, las Neurociencias, la Sociología.

Pero con todo ello se ha ido articulando todo un arsenal conceptual, metodológico y metódico propio del enfoque 'de la Complejidad' que, mutatis mutandi, ha ido trascendiendo todas aquellas disciplinas -o aquellas multi e interdisciplinas-que le aportaron uno u otro concepto o metódica. Pero hubo más: tal arsenal fue "retornando" a una u otra de dichas disciplinas, comenzó a ser empleado por ellas; y, por cierto, no siempre fueron solamente la noción o nociones, ni el método o métodos, que originariamente dicha disciplina aportara a la transdisciplinariedad.

Así, hoy se emplean las nociones de "caos", "tractores", "bifurcaciones", "espacio de fases" y "estructuras disipativas", para mencionar sólo algunas, en las más diversas disciplinas naturales, técnicas y sociales; y la comprensión de "redes en red" ha sido adoptada como "metáfora central" por casi todo el espectro disciplinario.

De modo que, lejos de contradecir -y mucho menos "eliminar"- a las disciplinas, el enfoque 'de la Complejidad' lo que hace es nutrirse de ellas para realimentarlas posteriormente con sus propias elaboraciones. Lo mismo realizan otros saberes transdisciplinarios como la Bioética Global y el Holismo Ambientalista.

Otra cuestión importante es distinguir entre disciplina y enfoque disciplinario. La transdisciplinariedad no elimina las disciplinas, pero sí pone fin al predominio de los enfoques 
disciplinarios, es decir, a la pretensión exagerada que supone que desde la perspectiva de una disciplina aislada se puede aportar un conocimiento totalizador sobre el mundo.

\section{La transdisciplinariedad y el diálogo de saberes}

Indudablemente, tal fructificación mutua -conceptual, metodológica y metódica- entre la transdisciplina y las disciplinas, las multidisciplinas y las interdisciplinas, implica, de suyo, la presencia de un "diálogo" entre sus respectivos saberes. Diálogo que, por parcial y localizado que sea al inicio, se va ampliando y profundizando después, a medida que se va tejiendo la madeja del corpus de saber transdisciplinario que va trazando "puentes" conceptuales, metódicos y/o metodológicos entre los saberes "dialogantes".

Esta característica de "lo transdisciplinario" -que comparte con lo multi e interdisciplinario y que profundiza ulteriormente- es otro de los aspectos que contribuyen también a la demarcación de los saberes contemporáneos ya mencionados que lo ponen en juego, con relación a otro de los rasgos del ideal clásico - moderno- de racionalidad: la disciplinarización del saber.

Como sabemos, dicho ideal fue constituyendo uno tras otro saberes encerrados en fronteras disciplinares, lo que, si bien constituyó en sus primeras etapas un proceso de diferenciación necesario y útil del anterior saber indiferenciado, concomitante además con el ideal analítico (desmembrar las totalidades -que se consideraban demasiado complejas, lo que para aquella época era sinónimo de complicadas, para ser aprehendidas de manera directa e inmediata- en sus partes para "analizarlas"), comenzó, a partir de cierto momento, a convertirse dialécticamente en su contrario, es decir, en algo que obstaculizaba en medida creciente la aprehensión de tales totalidades - para no hablar de los perjudiciales efectos de las "deformaciones disciplinarias" de unos u otros "especialistas" de tal o cual disciplina, cuya "jerga" especializada se fue tornando ininteligible para las otras disciplinas y los otros especialistas, qué decir para el-hombre-(y-la-mujer)-de-la-calle.

Michel Foucault ha argumentado extensamente acerca del poder-disciplinario, ese usufructo (como tendremos ocasión de constatar cuando nos concentremos, en capítulos posteriores, en la caracterización compleja de la vida cotidiana)² de las desiguales-circuns-

2 Como en el capítulo VII: Saber social, complejidad y vida cotidiana (ver: https://goo.gl/pzvhdt). 
tancias-en-favor-de-algunos (los especialistas de una u otra disciplina) y en-desfavor-deotros (los no pertenecientes a las mismas), que ha caracterizado, y sigue caracterizando, al ejercicio de los saberes disciplinarios. Posiblemente todos hemos sentido, en una u otra ocasión, lo difícil que se torna ser aceptado por "los expertos" especializados en una u otra disciplina cuando no se procede de la misma y se intenta vincularse con ella. Tales conformaciones (prácticas) de saber-poder-disciplinario han sido -y lo son aún- uno de los principales obstáculos para el diálogo multi, inter y transdisciplinario.

Por cierto, retornando a la aludida comprensión moderna de "lo complejo" como sinónimo de "lo complicado", resultó que el pathos analítico que era concomitante a los esfuerzos disciplinarios, a pesar de los indudables y magníficos logros científicos y técnicos que hizo posible, conocidos por todos, no fue capaz, sin embargo, de realizar aquella aspiración inicial suya de, una vez aprehendidas analíticamente (es decir, analizadas) las partes, volverlas a reunir para proceder entonces, pertrechados ya con ese saber analítico acerca de las mismas, a obtener la nueva "cosecha" de un saber sintético acerca de "lo complicado" (es decir, "o complejo" para aquella época), de las totalidades de origen. Era como si la Complejidad eludiera al saber analítico.

Hoy sabemos por qué. Aquella empresa analítica de separar en partes las totalidades nos privaba de aprehender precisamente lo que genera la Complejidad: las interacciones internas (y no cualesquiera de ellas, sino las de carácter no-lineal) entre las partes (que entonces ya no son "partes", sino que constituyen "componentes" de algo que las trasciende). La ciencia analítica tiene que contentarse, por su propia naturaleza, con aprehender las interacciones externas entre partes que ya "no componen" algo mayor (la tercera ley de Newton, con su aprehensión de la universalidad de la acción y la reacción, cada una de ellas externa a la otra parte, es la formulación paradigmática de tales circunstancias).

Por el contrario, para el pensamiento 'de la Complejidad', "lo complejo" no es ya más sinónimo de "lo complicado"; "lo complejo" es sencillamente eso, "complejo", y como tal debe ser aprehendido. Pero para ello la ciencia analítica no nos ha legado demasiados medios y herramientas cognitivas. Y la empresa de elaborarlas ha sido, en verdad, la historia, durante buena parte del siglo XX, de la eclosión del pensamiento 'de la Complejidad'.

Y para ello ha habido que renunciar a esa desmembración en partes de las totalidades y elaborar medios conceptuales, metodológicos y metódicos (elaboración que está lejos de 
haber concluido, por "lo joven", epocalmente hablando, del esfuerzo) para su aprehensión inmediata como totalidades complejas. No es sorprendente, entonces, que la metáfora de "la red de redes" o de "redes en red" se haya convertido en la central para el pensamiento o enfoque 'de la Complejidad'.

En dicha comprensión - de índole holista- todo el saber-acerca-de-las-partes puede -y debe-aprovecharse, pero como aquello que nos permite proceder a su ulterior caracterización como componentes tramados en las aludidas redes-en-red. Y el centro de gravedad de esos esfuerzos holistas es precisamente la caracterización de la dinámica procesual de tales redes, sean entre átomos (moléculas, sólidos, líquidos y/o gases); entre moléculas (macromoléculas, células); entre células (tejidos, órganos, organismos vivos); entre organismos vivos (poblaciones, especies); entre seres humanos (grupos sociales, sociedades); entre estrellas (agrupaciones estelares, galaxias); entre galaxias (constelaciones galácticas; la metagalaxia), etc. Y cada una de tales redes constituye en sí misma sólo un nodo tramado en las redes de mayor complejidad.

Pero el "diálogo" entre saberes disciplinarios, multi, inter y transdisciplinarios no es el único que se constata en el decurso del saber contemporáneo. Ni es el único necesario. El ideal clásico -moderno- de racionalidad, como tuvimos ocasión de tratar en los dos primeros capítulos, ${ }^{3}$ nos ha legado otras múltiples dicotomías cognitivas -y de otra índole- que urge trascender. Y para ello es imprescindible poner en juego otros "diálogos" entre los polos "dicotomizados".

\section{El diálogo entre diferentes culturas civilizatorias y sus saberes respectivos}

En los primeros capítulos nos referimos a la perjudicial división que hemos heredado entre "la cultura científica" (identificada con las ciencias exactas, naturales y/o técnicas, es decir, las consideradas "duras") y "la cultura humanística" (identificada con las ciencias sociales y humanas, consideradas "suaves" o "blandas"). A tal dicotomía se le so-

3 Los primero dos capítulos del libro son I. El nuevo saber en construcción y las ciencias sociales, II. La complejidad y el nuevo ideal de racionalidad (ver: https://goo.gl/pzvhdt). 
brepone, en Occidente, la del saber y la cultura occidental y el saber y la cultura oriental (entendidos estos últimos en ocasiones en sentido lato, es decir, todo saber y cultura no occidentales -incluidos entonces, por ejemplo, el saber y la cultura del África subsahariana y el saber y la cultura islámico-musulmana-, y en ocasiones en sentido estrecho, como saber y cultura del Extremo Oriente).

No es un secreto que el saber y la cultura occidentales de la modernidad han pretendido $-\mathrm{y}$, de hecho, han ejercido- un papel hegemónico con relación a todos esos otros saberes y culturas. El colonialismo primero, el neocolonialismo después y ahora la globalización de signo neoliberal han vehiculado e instrumentalizado tales prácticas cognitivas y culturales (y otras mucho más crudas) hegemonizantes.

Componente indispensable de la necesaria y urgente superación liberadora y emancipadora de tales hegemonías cognitivas y culturales es, sin dudas, el diálogo entre las diferentes culturas civilizatorias y entre sus respectivos saberes. Debe apuntarse por cierto que, en algunas de las culturas no-occidentales, la comprensión holista y transdisciplinaria -y, en ocasiones, incluso la jerarquización de las interacciones nolineales (como en la medicina tradicional oriental con su secular visión "en redes")- se ha mantenido mucho más incólume (a pesar de los intentos coloniales, neocoloniales y neoliberal-globalizadores de entronizar en sus respectivas regiones de impacto la racionalidad analítica moderna); y, por lo mismo, el diálogo intercultural e inter-civilizatorio con ellas puede, en efecto, fertilizar ulteriormente los actuales esfuerzos de occidente por trascender el ideal moderno de racionalidad.

Pero no es el aludido "centrismo occidental" (respecto a todo lo no occidental) el único que padecemos -y a veces ejercemos, haciéndolo padecer a otros- en nuestra contemporaneidad. Los pueblos y naciones que pertenecemos al sur de esa "occidentalidad" conocemos muy bien otro de tales "centrismos": el "eurocentrismo" de nuestras antiguas metrópolis coloniales y neocoloniales.

A través de tal "eurocentrismo", han sido muchos los intentos -desafortunadamente en más de una ocasión exitosos- de imponernos modas, concepciones y metas de allende el Atlántico, que poco o nada tienen que ver con nuestras realidades y que las orientan y desvían en sentidos y direcciones que no favorecen nuestra identidad cultural y civilizatoria (sin desmedro de la legítima herencia cultural, hasta lingüística, que nos legaron). Y, lo 
que es peor, han sido muchos los oriundos de nuestro sur que se han sentido a menudo -y aún hoy se sienten- más identificados con maneras de pensar y de actuar, con las aspiraciones e ideales, con las realidades culturales y civilizatorias de ese lejano mundo europeo, que con las autóctonas.

Urge pues sustituir uno u otro de tales "centrismos", de inspiración hegemónica, con el diálogo fecundo entre saberes y culturas. Pero "diálogo" implica la actitud abierta aaprender-del-otro, el reconocimiento de que el otro tiene algo que enseñarnos, y viceversa.

No sólo la vieja Europa ha intentado imponer lo suyo a nuestro sur americano (entendido como el que comienza en la orilla meridional del Río Grande -región caribeña comprendida- y termina en Tierra del Fuego). De mucho más cerca ha venido otro "centrismo": el del american way of life. Pero, en tanto tenemos un capítulo de libro dedicado a la globalización neoliberal, lo trataremos en ese contexto.

\section{La irrupción del "lego" en el saber contemporáneo}

Un aspecto fundamental en el diálogo de saberes corresponde a la irrupción de los saberes desplazados, estigmatizados o simplemente devaluados por la preeminencia del saber científico en la modernidad.

El establecimiento del saber científico como saber hegemónico en la modernidad fue posible mediante un procedimiento de exclusión que, primero, delimitó los campos del saber científico por oposición al saber de la religiosidad y la escolástica medievales; y, segundo, delimitó el terreno del saber científico con respecto al saber cotidiano. La vida cotidiana y los saberes vinculados a ella fueron relegados a un plano menor, pues sólo el saber científico "positivo" era considerado capaz de conducirnos al conocimiento verdadero. Así, la riqueza de la vida cotidiana fue omitida, y se la consideró como pasividad receptora de los avances de la ciencia y el conocimiento científico.

El diálogo de saberes necesita y está promoviendo hoy el rescate de la legitimidad de esos saberes vinculados a la cotidianeidad, incluido el hombre común, sus conocimientos, valores y creencias. Este es uno de los aspectos más álgidos, pues persisten las conformaciones de poder-saber disciplinario, las que ejercen una notable influencia en aras de la anulación del diálogo y la omisión de los saberes no científicos. 
Los modos de irrupción del "lego" en el saber contemporáneo son variados. Entre ellos podemos destacar los siguientes:

- La activación del hombre común, que deja de ser receptor pasivo y demanda la participación y consideración del punto de vista de los no especialistas.

- La reconsideración del conocimiento aportado por culturas precedentes, o coexistentes, no dominantes.

- La consideración del espacio común a compartir por personas diferentes, verdaderos extraños morales y culturales que conviven y resuelven de conjunto problemas comunes.

- El diálogo con otras formas de saber, religiosas y esotéricas, que portan valores comunitarios.

- Y, finalmente, la demanda de una revaluación de las creencias.

Analicemos brevemente estos cinco aspectos. El hombre común ha dejado de ser un receptor pasivo de los avances de la ciencia y la técnica, y reclama su espacio en la discusión sobre la pertinencia del conocimiento científico, la necesidad y viabilidad de la introducción de los resultados de la ciencia y la técnica en la vida social. Esta participación puede estar signada negativamente por el anti-cientificismo y las tendencias alarmistas, pero no se reduce a ellas. Por su parte, se manifiesta positivamente en las preocupaciones y acciones ambientales de amplios sectores de la población mundial, en su rechazo a las guerras y al empleo indiscriminado de la ciencia y la técnica.

La cuestión epistemológica de interés en estos casos radica en que, desde la posición clásica de poder, los "especialistas" podrían rechazar el diálogo con los "legos", desconocedores, no especialistas, atribuyéndoles falta de conocimientos y competencias para el diálogo. Sin embargo, los resultados de la ciencia y la técnica se vuelcan sobre una sociedad mundial; sus efectos no son intra-científicos sino socioculturales, de modo que el punto de vista de los otros, los "hombres comunes", ha de considerarse en la construcción colectiva de saber. Aquí, como en el resto de los "diálogos" posibles y demandados a los que hemos hecho alusión anteriormente, la naturaleza sociocultural de los problemas que se someten a debate es el fundamento último de la necesidad de un diálogo de saberes 
que no excluya, sino que por el contrario incluya, la diversidad de perspectivas humanas y no humanas, pues el "otro" puede ser también "la Naturaleza".

Otro tanto ocurre con los conocimientos aportados por culturas precedentes, que fueron rechazados en épocas anteriores como no científicos. Esto ocurrió con el conocimiento médico de las culturas dominadas, su sabiduría higiénica, el conocimiento de las plantas medicinales; pero no sólo en medicina, sino también con el conocimiento social, psicológico, sobre las plantas y animales, y las correlaciones entre diversos componentes de los ecosistemas naturales. Hoy se vuelve a estos conocimientos y se establece un diálogo que no necesariamente, ni siempre, es equitativo y leal.

Las nuevas ciencias están prestando especial atención al conocimiento acumulado por diversas culturas, en busca de nuevas fuentes naturales para, por ejemplo, el desarrollo de medicamentos. Esto ha conducido a una reconsideración y diálogo de la medicina científica occidental con otras prácticas, como la medicina tradicional china o el conocimiento de plantas medicinales por parte de diversos pueblos indígenas y culturas. Sin embargo, en las condiciones actuales de dominación, se ha comenzado a desarrollar una nueva forma de hegemonismo y explotación, cuando el diálogo se torna, por ejemplo, biopiratería. Se busca en otros pueblos un conocimiento que se lleva a los centros de poder, se decodifica y se patenta para hacerlo funcionar, entonces, en el contexto de las bien conocidas relaciones de dominación y explotación.

Además, es necesario considerar la diversidad cultural coexistente no sólo en diversas regiones del mundo, sino también concentrada en las megalópolis del presente, donde conviven personas de diversas culturas, religiones, etnias y pueblos. Ello conduce a la necesidad de resolver asuntos comunes desde una diversidad de perspectivas de valoración y creencias coexistentes; los "extraños morales" que coexisten deben encontrar el bien común. Asuntos como la atención de salud o la educación de los hijos exigen un diálogo constante entre los saberes que esas culturas y personas portan, y no pueden continuar reduciéndose a los imperativos de dominación de una cultura o a un tipo de ideología científica impuesta a ellos.

No menos importante es la necesidad de un diálogo entre las ciencias y las creencias, así como una revaluación de estas últimas. En las diversas creencias religiosas se encuentran elementos de valor que han sido acumulados en las culturas, sociedades y pueblos, y que 
no pueden echarse a un lado cuando se trata de resolver asuntos culturales y sociales donde el saber científico tiene necesidad de considerar todas las aristas posibles. Un problema como, por ejemplo, el ambiental no puede desconocer las perspectivas científicas posibles, ni el aporte de las perspectivas ideológicas que, desde la religiosidad, aportan un punto de vista humano a considerar y con el cual es necesario dialogar.

No menos importante es la reconsideración de las creencias. La modernidad nos aportó un modelo de contraposición entre ciencia y creencia, verdad y error, que conduce a la imposibilidad de un diálogo entre ambas. Esta separación absoluta entre creencia y ciencia no es acertada. Ya en su memorable artículo "Filosofía de la inestabilidad", Ilya Prigogine (1989) señalaba el lado ideológico de toda producción científica. El conocimiento científico está preñado de valores y funciona ideológicamente.

Como ha argumentado Pablo González Casanova (2004) en el epígrafe "Ciencias y creencias" de su reciente libro Las nuevas ciencias y las humanidades. De la academia a la política, no sólo los orígenes de la ciencia y la filosofía occidentales deben buscarse en las creencias de los griegos del siglo VI a.C. y en las creencias judeo-cristianas. La separación que tuvo lugar a lo largo del desarrollo de la cultura occidental nos ha conducido al error de considerar a la ciencia libre de creencias:

Desde el siglo XIX, sin desafiar necesariamente al cristianismo y hasta dejando a Dios lo que es de Dios y a las ciencias lo que es de las ciencias, los filósofos, ideólogos y científicos de Occidente consolidan el espacio laico del conocimiento y de la política. Su hazaña los llevó a pensar que el mundo de las ciencias es del todo ajeno al de las creencias, los valores, el poder y los intereses. Eso era un error ignoto. Las creencias en las ciencias son tan fuertes o más que en las religiones. Las ideas y los sentimientos que entrañan remueven a los hombres y mujeres de ciencia, como a Monsieur Teste; ajustan sus molestias, avivan sus temores, sus esperanzas y sus terrores, sin que se muevan como querrían, libremente, y sólo movidos por las observaciones de las cosas y de sí mismos. Ciencias y creencias, costumbres y convenciones, sirven para decidir qué es y qué no es científico; qué es y qué no es una teoría, qué es y qué no es un método o prueba y qué es sólo filosofía (González Casanova, 2004: 360). 


\section{La importancia del diálogo de saberes para la solución de los problemas de nuevo tipo}

Como hemos esbozado en los temas anteriormente tratados, existe una notable coincidencia en la orientación de la Bioética Global, el Holismo Ambientalista y el pensamiento 'de la Complejidad' (incluidos aquí los desarrollos de la Nueva Epistemología). Orientación convergente que se expresa en la reconsideración del objeto de la ciencia y una comprensión del conocimiento que supera la dicotomía entre conocimiento y valor propia de la modernidad. Sin embargo, aún en la actualidad, predomina la separación entre los especialistas que se ocupan de problemas bioéticos, ambientales y "complejos".

Existe un acercamiento mayor entre las ideas bioéticas y ambientalistas, de una parte, y las 'de Complejidad' y epistemológicas, de otra parte. Sin embargo, el tratamiento de los asuntos que se abordan desde estas perspectivas reclama constantemente un diálogo de saberes que las incluya y las aúne a otras perspectivas.

Sirvan de ejemplo de lo anterior asuntos tales como el hambre en el mundo, el calentamiento global y el cambio climático, el SIDA y las enfermedades reemergentes, el desarrollo de las biotecnologías y en especial la producción de alimentos transgénicos. En estos casos se constata la insuficiencia de los enfoques "específicos", "disciplinarios", aislados.

Analizados desde una perspectiva bioética, que privilegia la consideración de lo ético al interior de la ciencia y su producción de conocimientos y que incorpora la diversidad de actores sociales y la urgencia de un amplio diálogo entre ellos, quedan abiertas las incertidumbres de conocimiento -que son manejables en términos 'de Complejidad'-, las limitaciones del presupuesto clásico de objetividad -reconocidas por la Nueva Epistemología (de segundo orden) - y las consideraciones de futuro que se vislumbran con mayor claridad desde la perspectiva del Holismo Ambientalista.

Sin embargo, acercar estas perspectivas y abordar los problemas desde ellas al modo de parches engomados que reconstruyen una hoja de papel es absolutamente insuficiente. Se necesita un esfuerzo integrador transdisciplinario que las unifique en el análisis de los problemas. Y no se trata solamente de un deseo. El diálogo fructífero de saberes es posible por la comunidad de naturaleza de los problemas que abordan -problemas de nuevo tipo-y de las ideas que estas perspectivas de análisis tienen en común. 
Como vemos, entre ellas sobresalen la integración de conocimiento y valor; la reconsideración del objeto de la ciencia y el lugar de la incertidumbre en el conocimiento; la preocupación por el futuro y las consecuencias a mediano y largo plazo de las intervenciones prácticas de los seres humanos.

Por otra parte, ha ocurrido también que la transdisciplinariedad se ha erigido en una especie de código, como por ejemplo, en los casos de la denominada Carta de la Transdisciplinariedad (1994) y La transdisciplinariedad. Manifiesto (Nicolescu, 1996), ocasiones en que "lo transdisciplinario", mutatis mutandi, adquiere estatus de programa de acción; lo que proporciona diversas aristas polémicas susceptibles de ser debatidas.

A partir del próximo capítulo, el libro entra en un segundo nivel de generalidad: ${ }^{\mathrm{e}} \mathrm{l}$ del impacto de la actual revolución en el saber sobre el saber social en particular.

\section{Referencias}

González Casanova, Pablo (2004). Ciencias y creencias. En Las nuevas ciencias y las humanidades. De la academia a la política. Barcelona: Anthropos.

Carta de la transdisciplinariedad (1994). Convento de Arrábida, Portugal. Disponible en: http://basarab-nicolescu.fr/chart.php\#es

Nicolescu, B. (1996). La transdisciplinariedad. Manifiesto. México DF: Multiversidad Mundo Real Edgar Morin, A.C

4 Ver próximos capítulos: https://goo.gl/pzvhdt. 